\title{
All Cartilage No Stitch Type Tympanoplasty - A Prospective Study
}

Debdulal Chakraborty, ${ }^{1}$ Chiranjib Das, ${ }^{1}$ Pritam Chatterjee, ${ }^{1}$ Rajesh Hansda ${ }^{1}$

\section{Introduction:}

\section{$\underline{\text { ABSTRACT }}$}

Although temporalis fascia is the commonly used graft material for tympanoplasty, cartilage has become the material of choice in cases with eustachian tube dysfunction, bilateral disease, total or anterior perforation of tympanic membrane, tympanosclerosis etc. Cartilage slices $<0.5 \mathrm{~mm}$ thick are similar to the tympanic membrane in their acoustic properties. The present study is aimed to describe stitch-less type 1 tympanoplasty with sliced tragal cartilage-perichondrium and evaluate anatomical, audiological and cosmetic outcomes.

Materials and Methods

A prospective study was conducted from March 2014 to August 2016, in ENT department of a Government Medical College and Hospital, West Bengal, India. Primary tympanoplasty cases irrespective of age, size and site of perforation, laterality and eustachian tube function were included in the study. History of previous tympanoplasty or mastoid surgery and cases requiring ossicular reconstruction or mastoidectomy were excluded from the study. Sliced tragal cartilage-perichondrium graft of $0.2 \mathrm{~mm}$ thickness was placed in underlay fashion through trans-canal or end-aural route.

$\underline{\text { Results }}$

Among 95 cases 38 were male, 57 were female with age range between 7 to 68 years. Average operative time was 30 minutes. Graft take was successful in $97.89 \%$ of cases. Average air bone gap 12 months after operation was 13.03dB.

\section{Conclusion}

Sliced cartilage-perichondrium graft gives good balance between sufficient stability and adequate acoustic sensitivity. Moreover, no stitch technique reduces operative time and increases cosmesis.

Kevwords:

Tympanoplasty; Stitch-less; Cartilage

$\mathrm{T}$ The aim of tympanoplasty is to close tympanic membrane (TM) perforations, restore hearing, and reconstruct a healthy middle ear cavity. ${ }^{1,2}$ Since the introduction of tympanoplasty by Wullstein in 1952 and Zoellner in 1955, different types of graft materials have been used to reconstruct the tympanic membrane. ${ }^{3,4}$ These include temporalis fascia, perichondrium, cartilage, periosteum, vein, and fat etc. Presently, temporalis fascia is the most frequently used graft material. Although it is a highly successful procedure in $70-90 \%$ of normally ventilated middle ears, the prognosis is poorer in cases with eustachian tube dysfunction and defect of the entire tympanic membrane., ${ }^{1,2}$ The rigidity,

1 - Department of ENT, BSMCH, Bankura, West Bengal

\section{Corresponding author:}

Dr Chiranjib Das

email: chirubata.das.87@gmail.com stiffness and bradytrophic metabolism of cartilage play an important role in resistance against retraction and graft failure. ${ }^{5}$ So during the last decade, there has been a renewal of interest in the use of cartilage with surgeons reporting improved outcomes when compared with temporalis fascia. ${ }^{6}$ Although, there have been concerns that cartilage may affect adversely acoustic transfer and hearing, studies have shown that cartilage slices $<0.5 \mathrm{~mm}$ thick are similar to the tympanic membrane in their acoustic properties. ${ }^{7}$ The present study is aimed to describe stitch-less type 1 tympanoplasty with sliced tragal cartilage-perichondrium graft and evaluate the anatomical, audiological and cosmetic outcomes.

\section{Materials and Methods}

The present prospective study was conducted in the ENT department of a Government Medical College and 


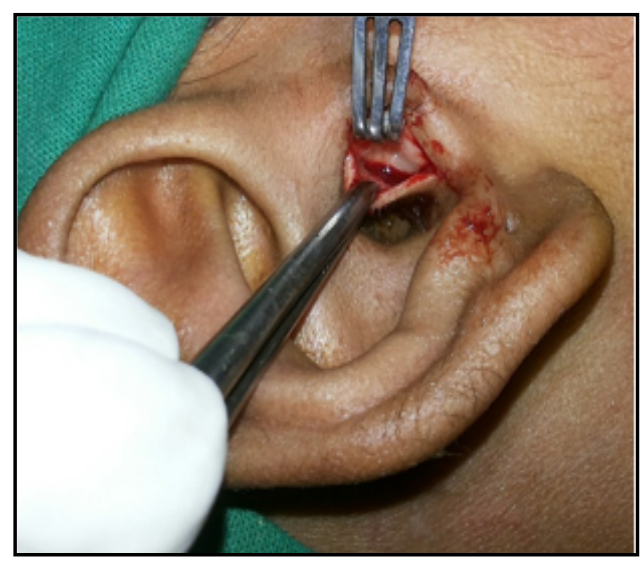

Fig. 1. Harvesting tragal cartilage with perichondrium

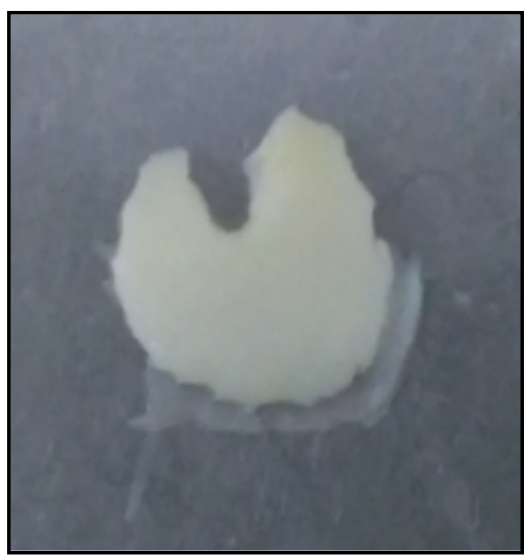

Fig. 2. Final shape of cartilageperichondrium graft

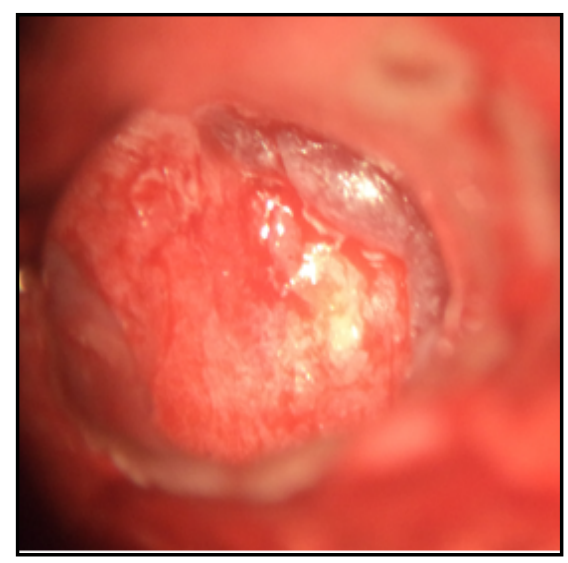

Fig. 3. After graft placement
Hospital, West Bengal, India, over the period of $2 \frac{1}{2}$ years from March 2014 to August 2016. Primary type 1 tympanoplasty cases irrespective of age, size and site of perforation, laterality and eustachian tube function were included in the study. In all cases the ear was dry and with normal middle ear mucosa for at least one month prior to surgery. History of previous tympanoplasty or mastoid surgery, discharging ear, cases requiring ossicular reconstruction or mastoidectomy were excluded from the present study. Those without sufficient followup for one year after surgery, without preoperative or postoperative hearing tests were also excluded.

A thorough history of the patients was taken including age, sex, socioeconomic background, side and duration of disease, history of previous ear surgery etc. Clinical evaluation of the ear included site and size of perforation, presence of adhesive changes, tympanosclerosis or retraction, and condition of middle ear mucosa. Regional and systemic examinations were also done. Pure tone audiometry and tympanometry were done in all patients.

After proper preoperative evaluation, patients were operated under local or general anaesthesia as required. End-aural or trans-canal route was selected according to the shape and size of external auditory canal and perforation. End-aural incision was limited within external auditory canal in all cases. Local infiltration was done with $2 \%$ lignocaine plus $1: 2,00,000$ adrenaline. Margin of the perforation was made raw. Tympanomeatal flap was raised and handle of malleus was denuded. Ossicular integrity and mobility was checked. After giving incision on medial part of tragus, cartilage was harvested. A lateral cartilaginous bridge of about $2 \mathrm{~mm}$ was left for aesthetic reason (Fig. 1). Cartilage graft was shaped and sliced to 0.2 $\mathrm{mm}$ thickness with the help of cartilage slicer, keeping perichondrium on one surface. Cartilage is stripped approximately $0.2 \mathrm{~mm}$ circumferentially from the edge using circular knife. A v-shaped notch is made from center to periphery to accommodate malleus handle (Fig. 2 ). The graft was placed over the handle of malleus and medial to tympanic annulus with perichondrium facing laterally extending onto external auditory canal (Fig. 3). Absorbable gelatin sponge was placed over the graft. It was also used to pack the external auditory canal and secure incision line (Fig. 4). Patients were discharged next day with antibiotics. Each case was reviewed at 1 week, 3 week, 2 months, 6 months and 1 year (Fig. 5). Post-operative pure tone audiometry was done at 6 months and 1 year.

Results

In the study period we operated on 100 cases. But five cases were lost to follow up. Among 95 cases 38 were male, 57 were female with age range between 7 to 68 years (Table I). Most were in the 3rd decade of life. Average operative time was 30 minutes. Two months after operation, graft take was successful in 24 out of 24 cases $(100 \%)$ in small perforation, 54 out of 56 cases $(96.43 \%)$ in medium perforation, and 13 out of 15 cases $(86.67 \%)$ in large perforation (Table II). Six months 


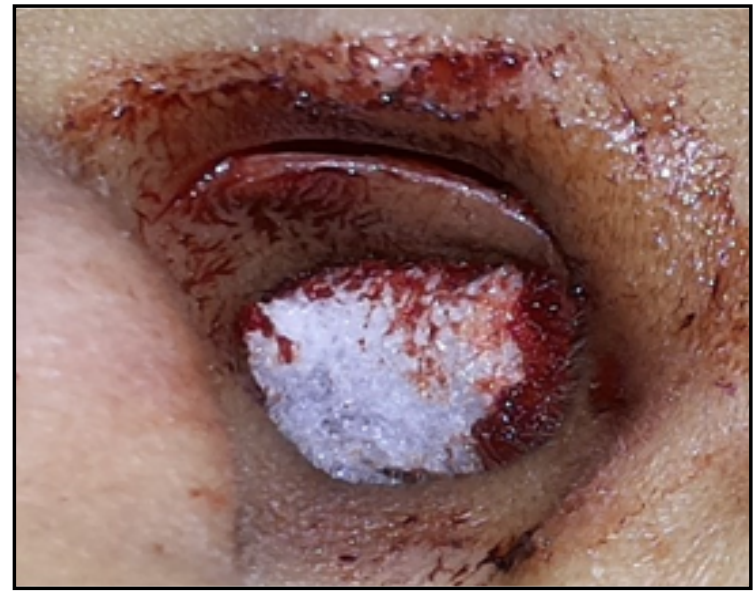

Fig. 4. Incision line secured with gelatin sponge

after operation, one out of two cases in each group of medium and large perforation healed spontaneously. So the final successful graft take was $97.89 \%$. Two cases of residual perforation were treated at the end of 12 months after operation, one with chemical cautery, another with fat grafting. Average Air Bone Gap (ABG) 6 months after operation was $14.78 \mathrm{~dB}, 18.54 \mathrm{~dB}$ and $22.69 \mathrm{~dB}$ in small, medium and large perforation group respectively (Table III). Average ABG 12 months after operation was $12.29 \mathrm{~dB}, 13.56 \mathrm{~dB}$ and $14.09 \mathrm{~dB}$ in small, medium and large perforation group respectively. Wound healing of the graft taking site was perfectly well in all patients.

\section{Discussion}

The main purpose of tympanoplasty is to repair tympanic membrane perforation, thus protecting middle ear from infections and improving the hearing. ${ }^{1,2}$ Factors affecting the success rate of tympanoplasty are age, site and size of perforation, condition of middle ear mucosa, function of the eustachian tube, type of graft used, and surgical experience. ${ }^{8,9,10}$ Temporalis fascia has been the most commonly used graft material for tympanoplasty, and the success rate is nearly $90 \% .^{11,12}$ Causes of tympanoplasty failure using a temporalis fascia graft are poor eustachian tube function, bilateral disease, large and anterior perforation, tympanosclerosis, revision surgery, tobacco smoking and low socioeconomic condition. ${ }^{13,14} \mathrm{~A}$ more rigid, and more resorption and retraction resistant graft material,

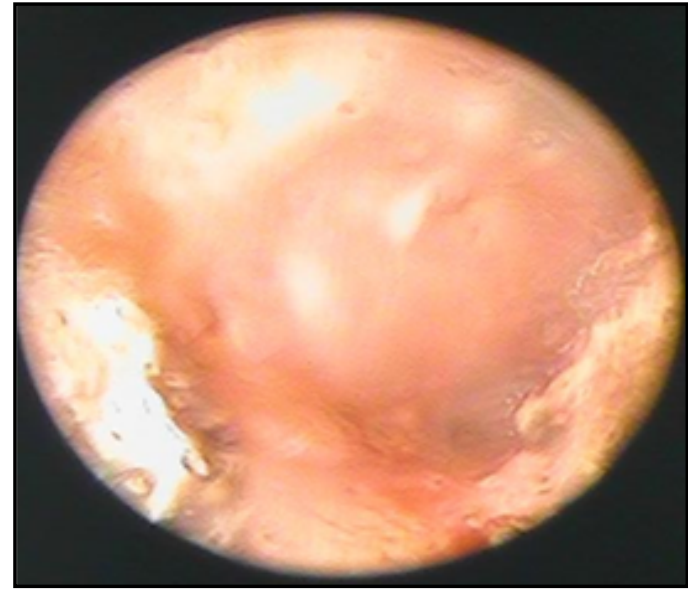

Fig. 5. 6 months post-operative photograph

may provide better success rates. Cartilage is formed mainly by type 2 collagen having higher tensile strength than type 1 collagen found in fascia, which contributes to its stability. ${ }^{15}$ Cartilage contributes minimally to an inflammatory tissue reaction. A cartilage graft has a very low metabolic rate. It receives its nutrients by diffusion and perichondrial attachment on one side increases its

Table I: Age and Sex distribution of the patients

\begin{tabular}{|c|c|c|c|}
\hline 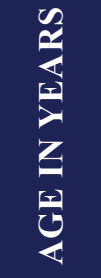 & $\frac{\sqrt[6 x]{3}}{8}$ & $\sum_{\substack{x \\
x}}^{\frac{5 x}{3}}$ & $\stackrel{\theta}{\ominus}$ \\
\hline$\leq 10$ & 2 & 3 & 5 \\
\hline $11-20$ & 13 & 14 & 27 \\
\hline $21-30$ & 11 & 22 & 33 \\
\hline $31-40$ & 6 & 10 & 16 \\
\hline $41-50$ & 3 & 4 & 7 \\
\hline $51-60$ & 2 & 3 & 5 \\
\hline$\geq 61$ & 1 & 1 & 2 \\
\hline Total & 38 & 57 & 95 \\
\hline
\end{tabular}


Table II: Distribution of patients according to pre-operative and post-operative condition of TM

\begin{tabular}{|c|c|c|c|c|c|}
\hline & & \multicolumn{4}{|c|}{ CONDITION OF TM IN POST-OPERATIVE PERIOD } \\
\hline & & \multicolumn{2}{|c|}{2 MONTHS } & \multicolumn{2}{|c|}{6 MONTHS } \\
\hline & & INTACT & PERFORATED & INTACT & PERFORATED \\
\hline \multirow{3}{*}{$\begin{array}{l}\text { Condition of } \\
\text { TM in pre- } \\
\text { operative period }\end{array}$} & $\begin{array}{c}\text { Small } \\
\text { perforation }\end{array}$ & 24 & $\mathbf{0}$ & 24 & $\mathbf{0}$ \\
\hline & $\begin{array}{c}\text { Medium } \\
\text { perforation }\end{array}$ & 54 & 2 & 55 & 1 \\
\hline & $\begin{array}{c}\text { Large } \\
\text { perforation }\end{array}$ & 13 & 2 & 14 & 1 \\
\hline \multicolumn{2}{|c|}{ Total } & $91(95.79 \%)$ & $4(4.21 \%)$ & $93(97.89 \%)$ & $2(2.11 \%)$ \\
\hline
\end{tabular}

viability. Even if the cartilage becomes non-viable it remains functional mechanically. It is easy to work with because of its pliability, and resists deformation from pressure variations. ${ }^{16}$ The main advantage of cartilage tympanoplasty is that epithelisation may continue over the cartilage surface even if the graft detaches anteriorly. ${ }^{17}$ The other advantage is that cartilage tympanoplasty avoids synechia formation between the graft and promontory, because there is no need to use absorbable gelatin sponge in the middle ear to support the graft. ${ }^{17}$ Therefore, cartilage has now become the preferred graft material over temporalis fascia in high risk perforations.

Cartilage graft was first described Heerman in 1962. ${ }^{18}$ Mirko Tos described 23 methods of cartilage tympanoplasty to reconstruct the eardrum and proposed a classification into six main groups. We performed tympanoplasty with cartilage-perichondrium composite island grafts, which falls under group $\mathrm{C}$ of Tos classification (2008). ${ }^{19}$ Khan et al. used shield-

Table III: Comparison of mean pre-operative, 6 months post-operative and 12 months post-operative ABG between patients with small, medium and large TM perforations

\begin{tabular}{|c|c|c|l|}
\hline & PRE-OPERATIVE ABG & \multicolumn{1}{|c|}{$\begin{array}{c}\text { MONTHS } \\
\text { (IN DECIBEL) } \\
\text { POST- } \\
\text { OPONTHS POST- } \\
\text { OPEATIVE ABG } \\
\text { (IN DECIBEL) }\end{array}$} & $\begin{array}{c}\text { OPERATIVE } \\
\text { ABG (IN } \\
\text { DECIBEL) }\end{array}$ \\
\hline Small perforation & 25.56 & 14.78 & 12.29 \\
\hline Medium perforation & 31.76 & 18.54 & 13.56 \\
\hline Large perforation & 38.53 & 22.69 & 14.09 \\
\hline
\end{tabular}


Table IV: Comparisons of graft take success rate with previous authors

\begin{tabular}{|c|c|c|c|}
\hline AUTHOR & TECHNIQUE & NO. OF PATIENTS & SUCCESS RATE \\
\hline Amedee RG et al (1989) $)^{24}$ & Palisade cartilage & 52 & $100 \%$ \\
\hline Dornhoffer JL (1997) $)^{12}$ & Cartilage & 22 & $100 \%$ \\
\hline Kazikdas $\mathrm{KC}$ et al $(2007)^{1}$ & Palisade cartilage & 23 & $95.70 \%$ \\
\hline Kalcioglu MT et al (2009) & Cartilage island & 60 & $95 \%$ \\
\hline Neumann A et al $(2010)^{5}$ & Palisade cartilage & 29 & $100 \%$ \\
\hline Chen XW et al $(2010)^{30}$ & $\begin{array}{l}\text { Perichondrium/cartilage } \\
\text { composite graft }\end{array}$ & 74 & $92 \%$ \\
\hline Khan MM et al (2011) & Sliced tragal cartilage & 223 & $98.20 \%$ \\
\hline Yurttas V et al (2014) $)^{17}$ & Cartilage island & 87 & $93.10 \%$ \\
\hline Present study (2016) & $\begin{array}{l}\text { Sliced tragal cartilage } \\
\text { perichondrium } \\
\text { composite graft }\end{array}$ & 95 & $95.79 \%$ \\
\hline
\end{tabular}

sliced tragal cartilage-perichondrium composite graft and their success rate was $98.20 \%$ (Table IV). ${ }^{20}$ Neumann et al. reported a graft take rate of $100 \%$ in their palisade cartilage tympanoplasty study. ${ }^{5}$ Sismanis et al. reported $93.5 \%$ success rate in their revision tympanoplasty cases..$^{21}$ In the present study, graft take rate was $97.89 \%$. In 4 cases residual perforations were observed. These perforations were between the remnant tympanic membrane and cartilage part of the graft due to malposition of the cartilage. Tek et al. reported 3 graft failures in their cartilage tympanoplasty series, and they were anterior perforations. ${ }^{22}$ The perceived disadvantage of the cartilage graft is that it creates an opaque tympanic membrane, which could potentially obscure post operative examination of any middle ear pathology. ${ }^{23}$

Although the graft-take rate is high in cartilage tympanoplasty, hearing gain might not be satisfactory due to its effect on tympanic membrane elasticity.
According to Zahnert's experimental study, cartilage slices $<0.5 \mathrm{~mm}$ thick are similar to the tympanic membrane in terms of their acoustic properties. ${ }^{7}$ Overbosch in 1971 was first to describe a microslice technique to improve the acoustic properties of the reconstructed tympanic membrane. He cut cartilages by a dermatome into plates with thickness of 0.2-1 $\mathrm{mm} .{ }^{24}$ Recent studies have shown that no statistically significant difference exists in temporalis fascia and cartilage tympanoplasties in terms of postoperative hearing results. ${ }^{11,12,25}$ In 2004, Gierek et al. observed that there was no significant hearing difference between cartilage and temporalis fascia. ${ }^{26}$ Couloinger et al. observed 59 cartilage graft tympanoplasties and 20 temporalis fascia graft tympanoplasties in 2005 and they reported no post-operative hearing difference between the two groups. ${ }^{27}$ Gerber et al. compared the cartilage to temporalis fascia in a frequency-specific manner and again no significant difference was observed. They 
found the average improvement in the air conduction threshold to be $10 \mathrm{~dB} \cdot{ }^{11}$ In the present study, satisfactory hearing results were observed. Moreover, ABG closure continued to improve in patients with large perforation during the follow-up period. The connection between cartilage graft and tympanic membrane and malleus is important for acoustic transfer. Furthermore, large eardrum perforation may require longer time for healing and tissue remodeling between the cartilage graft and original tympanic membrane, and even the malleus. ${ }^{28}$ So longer duration of follow up is necessary to comment regarding the improvement of hearing and graft viability.

\section{Conclusion}

Cartilage graft is experiencing a renaissance in tympanoplasty in high risk perforations. It gives otologists a reliable armamentarium in reconstruction of tympanic membrane. Cartilage of $<0.5 \mathrm{~mm}$ thickness maintains a perfect balance between sufficient stability and adequate acoustic sensitivity. Moreover, no stitch technique is minimally invasive, reduces operative time, hospital stay and yields cosmetically better results.

\section{References}

1. Kazikdas KC, Onal K, Boyraz I, Karabulut E. Palisade cartilage tympanoplasty for management of subtotal perforations: a comparison with the temporalis fascia technique. Eur Arch Otorhinolaryngol. 2007; 264: 985-9

2. Indorewala S. Dimensional stability of free fascia grafts: clinical application. Laryngoscope 2005; 115: 278-82

3. Zollner F. The principles of plastic surgery of the sound conducting apparatus. J Laryngol Otol. 1955; 69: 657-9

4. Wullstein H. Funktionelle Operationen im Mittelohr mit Hilfe des Freien Spaltappentransplantates. Arch Otorhinolaryngol. 1952; 161: 422-35

5. Neumann A, Kevenhoerster K, Gostian AO. Long-term results of palisade cartilage tympanoplasty. Otol Neurotol. 2010; 31: 936-9

6. Onal K, Arslanoglu S, Oncel S, et al. Perichondrium/cartilage island flap and temporalis muscle fascia in Type I tympanoplasty. J Otolaryngol Head Neck Surg. 2011; 40: 295-9

7. Zahnert T, Huttenbrink K-B, Murbe D, et al. Experimental investigations of the use of cartilage in tympanic membrane reconstruction. Am J Otol. 2000; 21: 322-8
8. Westerberg J, Harder H, Magnuson B, Westerberg L, Hydén D. Ten-year myringoplasty series: does the cause of perforation affect the success rate? J Laryngol Otol. 2011; 125: 126-32

9. Mohamad SH, Khan I, Hussain SS. Is cartilage tympanoplasty more effec $\neg$ tive than fascia tympanoplasty? A systematic review. Otol Neurotol. 2012; 33: 699-705

10. Lin YC, Wang WH, Weng HH, Lin YC. Predictors of surgical and hearing long-term results for inlay cartilage tympanoplasty. Arch Otolaryngol Head Neck Surg. 2011; 137: 215-9

11. Gerber MJ, Mason JC, Lambert PR. Hearing results after primary cartilage tympanoplasty. Laryngoscope 2000; 110: 1994-96

12. Dornhoffer JL. Hearing results with cartilage tympanoplasty. Laryngoscope. 1997; 107: 1094-9

13. Onal K, Uguz MZ, Kazikdas KC, Gursoy ST, Gokce H. A multivariate analysis of otological, surgical and patientrelated factors in determining success in myringoplasty. Clin Otolaryngol. 2005; 30: 115-20

14. Pinar E, Sadullahoglu K, Calli C, Oncel S. Evaluation of prognostic factors and middle ear risk index in tympanoplasty. Otolaryngol Head Neck Surg. 2008; 139: 386-90

15. Yegin Yakup, Çelik Mustafa, Koç Arzu Karaman, Küfeciler Levent, Elbistanlı Mustafa Suphi, Kayhan Fatma Tülin. Comparison of temporalis fascia muscle and full-thickness cartilage grafts in type 1 pediatric tympanoplasties. Braz. J Otorhinolaryngol. 2016; 82: 695-701

16. Yung, M. Cartilage Tympanoplasty: Literature Review. J Laryngol Otol. 2008; 122, 663-72

17. Yurttas V, Yakut F, Kutluhan A, Bozdemir K. Preparation and placement of cartilage island graft in tympanoplasty. Braz J Otorhinolaryngol. 2014; 80: 522-6

18. Heermann J. Experiences with free transplantation of faciaconnective tissue of the temporalis muscle in tympanoplasty and reduction of the size of the radical cavity. Cartilage bridge from the stapes to the lower border of the tympanic membrane. Z Laryngol Rhinol Otol. 1962; 41: 141-55

19. Tos M. Cartilage tympanoplasty methods: proposal of a classification. Otolaryngol. Head Neck Surg. 2008; 139: 747-58

20. Khan MM, Parab SR. Primary cartilage tympanoplasty: our technique and results. Am J Otolaryngol. 2011; 32: 381-7

21. Sismanis A, Dodson K, Kyrodimos E. Cartilage "shield" grafts in revision tympanoplasty. Otol Neurotol. 2008; 29:330-3

22. Tek A, Karaman M, Uslu C. et al. Audiological and graft take results of cartilage reinforcement tympanoplasty (a new technique) versus fascia. Eur Arch Otorhinolaryngol. 2012; 269: $1117-26$

23. Ghanem MA, Monroy A, Alizadeh FS, Nicolau Y, Eavey RD. (2006) Butterfly Cartilage Graft Inlay Tympanoplasty for Large Perforations. Laryngoscope 2006; 116: 1813-6

24. Overbosch HC. Homograft myringoplasty with microsliced septal cartilage. Proc Otorhinolaryngol. 1971; 33: 356-7 
25. Amedee RG, Mann WJ, Riechelmann H. Cartilage palisade tympanoplasty. Am J Otol. 1989; 10: 447-50.

26. Gierek T, Slaska-Kaspera A, Majzel K, Klimczak-Gotqbm L. Results of myringoplasty and type I tympanoplasty with the use of fascia, cartilage and perichondrium grafts. Otolaryngologia Polska 2004; 3: 529-33

27. Couloigner V, Baculard F, El Bakkouri W, et al. Inlay butterfly cartilage tympanoplasty in children. Otol Neurotol. 2005; 26: 247Y51

28. Wu PW, Wang WH, Huang CC, Lee TJ, Huang CC. Comparison of Short- and Long-term Hearing Outcomes of Successful Inlay Cartilage Tympanoplasty Between Small and Large Eardrum Perforations. Clinical and Experimental Otorhinolaryngology 2015; 8: 359-63

29. Kalcioglu T, Firat Y, Selimoglu E. Cartilage tympanoplasty with island technique: a comparison with the temporalis muscle fascia technique. Int Adv Otol. 2009; 5: 45-50

30. Chen XW, Yang H, Gao RZ, Yu R, Gao ZQ (2010). Perichondrium/cartilage composite graft for repairing large tympanic membrane perforations and hearing improvement. Chin Med J (Engl). 2010; 123: 301-4. 